\title{
Rhodomyrtus tomentosa (Aiton) Hassk. ethanol extract and rhodomyrtone: a potential strategy for the treatment of biofilm-forming staphylococci
}

\begin{abstract}
Correspondence
Supayang Piyawan

Voravuthikunchai

supayang.v@psu.ac.th
\end{abstract}

Received 10 April 2011

Accepted 25 July 2011

\author{
Jongkon Saising, ${ }^{1,2}$ Metta Ongsakul ${ }^{1}$ \\ and Supayang Piyawan Voravuthikunchai ${ }^{1,2}$
}

\author{
${ }^{1}$ Department of Microbiology, Faculty of Science, Prince of Songkla University, Hat Yai, \\ Songkhla 90112, Thailand \\ ${ }^{2}$ Natural Products Research Center, Faculty of Science, Prince of Songkla University, Hat Yai, \\ Songkhla 90112, Thailand
}

\begin{abstract}
The anti-staphylococcal activity of an ethanol extract of Rhodomyrtus tomentosa and its pure compound, rhodomyrtone, as well as their effects on staphylococcal biofilm formation and biofilm-grown cells were assessed. MIC and minimal bactericidal concentration values of the ethanol extract and rhodomyrtone against planktonic cultures and biofilms of five clinical strains each of Staphylococcus aureus and Staphylococcus epidermidis, and American Type Culture Collection (ATCC) strains of both species, were 32-512 and 0.25-2 $\mathrm{g} \mathrm{ml}^{-1}$, respectively. Results from time-kill studies indicated that rhodomyrtone at a concentration of $4 \times \mathrm{MIC}$ could reduce the number of Staphylococcus aureus ATCC 25923 and Staphylococcus epidermidis ATCC 35984 cells by $99.9 \%$ within 3 and 13 h, respectively. The ability of rhodomyrtone and the ethanol extract to prevent biofilm formation and kill mature biofilms was assessed: both demonstrated better activity than vancomycin at inhibiting staphylococcal biofilm formation. In addition, the viability of $24 \mathrm{~h}$ and 5-day staphylococcal biofilm-grown cells decreased after treatment with the ethanol extract and rhodomyrtone. The ability to reduce biofilm formation and kill mature biofilms occurred in a dose-dependent manner. Scanning electron microscopy clearly confirmed that treatment with rhodomyrtone at $16 \times \mathrm{MIC}$ could reduce $24 \mathrm{~h}$ biofilm formation and the numbers of staphylococci, whilst at $64 \times \mathrm{MIC}$ this compound destroyed the organisms in the 5 -day established biofilm. These results suggest that rhodomyrtone has the potential for further drug development for the treatment of biofilm-forming staphylococcal infections.
\end{abstract}

\section{INTRODUCTION}

Staphylococci are widely involved in minor and severe infections. Currently, these organisms are resistant to many commonly used antibiotics, and treatment of staphylococcal infections is becoming difficult due to the increase in antibiotic resistance of these organisms. Importantly, biofilm formation is often associated with antibiotic resistance in these organisms, and antimicrobial resistance in biofilmforming cells is increased compared with that in free-living cells (Cerca et al., 2005; Nishimura et al., 2006; Frank et al., 2007). Biofilm formation is one of the most important staphylococcal virulence factors. The formation of biofilm involves two stages: (i) initial adherence of bacterial cells to the host-cell surface or other materials; and (ii) the formation of a multilayered cell cluster surrounded by extracellular polysaccharide matrix (Götz, 2002). The production of extracellular polysaccharide matrix has been

Abbreviation: MBC, minimal bactericidal concentration. suggested to prevent the access of antibiotics to the bacterial cells embedded in the biofilm (Mah \& O'Toole, 2001). Consequently, effective agents are necessary to control biofilm-producing staphylococci.

Medicinal plants have been studied extensively as alternative antimicrobial therapeutic agents. An ethanol extract of Rhodomyrtus tomentosa leaves as well as rhodomyrtone, a pure compound in the acylphloroglucinol class isolated from the leaves of this medicinal plant species, have shown profound antibacterial activity against a wide range of Gram-positive pathogenic bacteria with low MIC values, comparable to available antibiotics including vancomycin (Saising et al., 2008; Limsuwan et al., 2009; Voravuthikunchai et al., 2010). Natural compounds from certain plants such as carvacrol, thymol and salvipisone have also been demonstrated to exert effects on staphylococcal biofilm (Kuźma et al., 2007; Nostro et al., 2007; Wang et al., 2009).

The aim of this study was to investigate further the ability of an ethanol extract of $R$. tomentosa leaves and pure 
Table 1. MIC and MBC values $\left(\mu \mathrm{g} \mathrm{ml}^{-1}\right)$ of $R$. tomentosa ethanol extract, rhodomyrtone and vancomycin against Staphylococcus aureus and Staphylococcus epidermidis isolated from acne lesions

\begin{tabular}{|c|c|c|c|c|c|c|}
\hline \multirow[t]{2}{*}{ Isolate } & \multicolumn{2}{|c|}{ Ethanol extract } & \multicolumn{2}{|c|}{ Rhodomyrtone } & \multicolumn{2}{|c|}{ Vancomycin } \\
\hline & MIC & MBC & MIC & MBC & MIC & MBC \\
\hline \multicolumn{7}{|c|}{ Staphylococcus aureus } \\
\hline NPRC 310 & 32 & 128 & 0.5 & 0.5 & 1.0 & 1.0 \\
\hline NPRC 313 & 32 & 128 & 0.5 & 1.0 & 0.5 & 1.0 \\
\hline NPRC 326 & 128 & 256 & 1.0 & 2.0 & 1.0 & 4.0 \\
\hline NPRC 334 & 32 & 64 & 0.5 & 2.0 & 1.0 & 4.0 \\
\hline NPRC 361 & 32 & 128 & 1.0 & 2.0 & 1.0 & 2.0 \\
\hline ATCC 25923 & 32 & 64 & 0.5 & 1.0 & 0.5 & 1.0 \\
\hline \multicolumn{7}{|c|}{ Staphylococcus epidermidis } \\
\hline NPRC 511 & 32 & 64 & 1.0 & 2.0 & 2.0 & 4.0 \\
\hline NPRC 522 & 32 & 64 & 1.0 & 2.0 & 1.0 & 2.0 \\
\hline NPRC 535 & 128 & 128 & 0.25 & 0.25 & 1.0 & 1.0 \\
\hline NPRC 576 & 128 & 512 & 0.25 & 1.0 & 1.0 & 2.0 \\
\hline NPRC 585 & 128 & 128 & 1.0 & 1.0 & 2.0 & 2.0 \\
\hline ATCC 35984 & 256 & 512 & 0.5 & 0.5 & 1.0 & 1.0 \\
\hline
\end{tabular}

rhodomyrtone to eradicate staphylococcal biofilms, as well as to study their effects on the biofilm-grown bacterial cells.

\section{METHODS}

Bacteria. Staphylococcus aureus $(n=5)$ and Staphylococcus epidermidis $(n=5)$ were isolated from acne lesions and identified on the basis of colony characteristics, Gram staining, and catalase and coagulase tests. The cultures were stored at $4{ }^{\circ} \mathrm{C}$ until use. The biofilm-forming strains Staphylococcus aureus ATCC 25923 and Staphylococcus epidermidis ATCC 35984 were included as controls.

Antimicrobial agents. Leaves of $R$. tomentosa (Aiton) Hassk. were dried and ground, and the powder was extracted with $95 \%$ ethanol. The ethanol was evaporated using a rotary evaporator and the extract was resuspended in $10 \%$ DMSO (Merck) before use. Rhodomyrtone was isolated according to a method described previously and dissolved in $10 \%$ DMSO (Saising et al., 2008). Vancomycin (Fluka) and DMSO were included as controls.

Determination of MICs and minimal bactericidal concentrations (MBCs). The MICs of antimicrobial agents were determined using a modified broth microdilution method (CLSI, 2006). Aliquots $(20 \mu \mathrm{l})$ of the ethanol extract and rhodomyrtone were diluted in a 96well microtitre plate to final concentrations of $1024-0.5$ and 32$0.06 \mu \mathrm{g} \mathrm{ml}^{-1}$, respectively, and $80 \mu \mathrm{l}$ Mueller-Hinton broth (MHB; Difco) was added to each well. One hundred microlitres of bacterial suspension $\left(10^{6}\right.$ c.f.u. $\left.\mathrm{ml}^{-1}\right)$ was added to each well and incubated at $35{ }^{\circ} \mathrm{C}$ for $16-18 \mathrm{~h}$. The MIC was read as the lowest concentration that completely inhibited bacterial growth. The $\mathrm{MBC}$ was assessed as the extract that gave significant MIC values by streaking the culture on trypticase soy agar (Difco). Experiments were carried out in triplicate.

Time-kill study. Staphylococcus aureus ATCC 25923 and Staphylococcus epidermidis ATCC 35984 were used as representative strains in time-kill kinetic experiments. An inoculum $\left(10^{6}\right.$ c.f.u. $\left.\mathrm{ml}^{-1}\right)$ of the growing cultures was added to trypticase soy broth (TSB; Difco) supplemented with rhodomyrtone at concentrations of $0.5 \times, 1 \times, 2 \times$ and $4 \times$ MIC and incubated at $35{ }^{\circ} \mathrm{C}$. Viable counts were determined by a drop plate method. Briefly, samples were collected at various time intervals and (a)

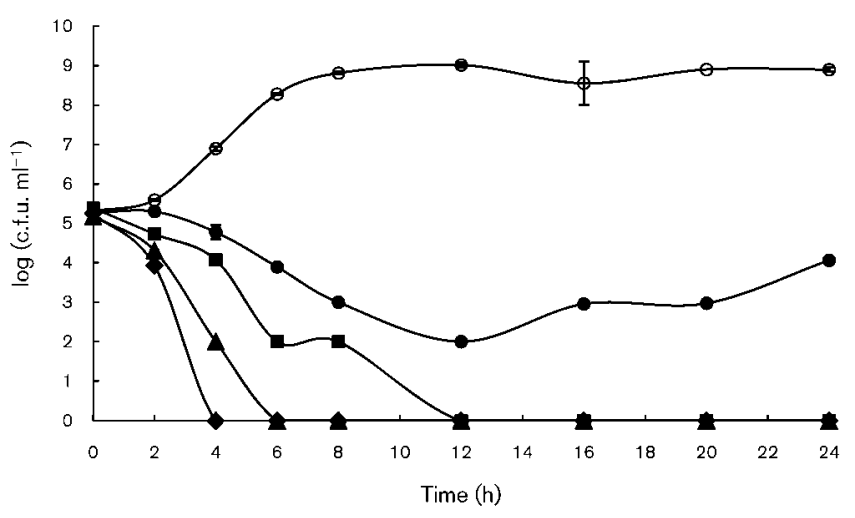

(b)

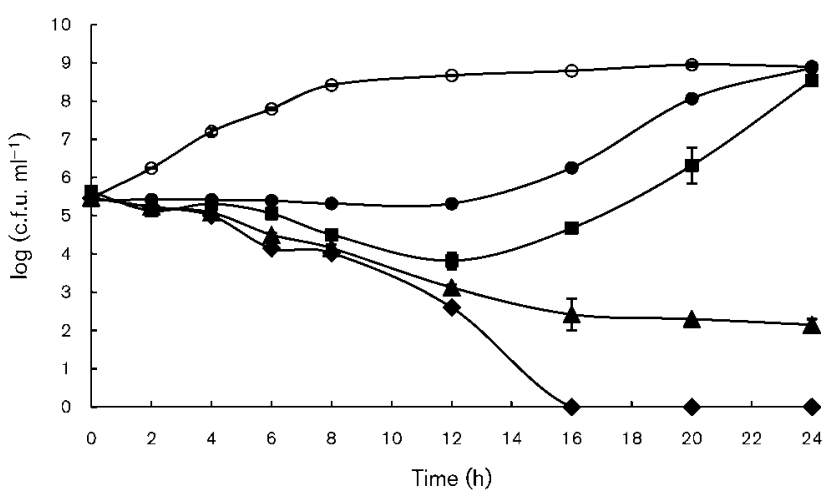

Fig. 1. Time-kill curves of Staphylococcus aureus ATCC 25923 (a) and Staphylococcus epidermidis ATCC 35984 (b) in the presence of rhodomyrtone at various concentrations. The limit of detection was 100 c.f.u. $\mathrm{ml}^{-1}$. $\bigcirc$, Control; ๑, 0.5× MIC; $\mathbf{\square}, \mathrm{MIC}$; $\Delta, 2 \times \mathrm{MIC} ;, 4 \times \mathrm{MIC}$. 
serially diluted tenfold. Each dilution was dropped onto a trypticase soy agar plate. The experiment was carried out in duplicate and the results were presented as mean log numbers of organisms \pm SEM.

Effect of $\boldsymbol{R}$. tomentosa ethanol extract, rhodomyrtone and vancomycin on biofilm formation. An experiment was performed according to the protocol of Karaolis et al. (2005) with slight modifications. Briefly, $100 \mu \mathrm{l}$ of an overnight culture grown in TSB was diluted to $10^{6}$ c.f.u. $\mathrm{ml}^{-1}$ and transferred to a 96 -well microtitre plate containing $20 \mu \mathrm{l}$ test antibacterial agents at subinhibitory concentrations and $80 \mu \mathrm{l} \mathrm{TSB}$. After incubation at $37{ }^{\circ} \mathrm{C}$ for $24 \mathrm{~h}$, the wells were washed twice with PBS, air-dried and stained with $200 \mu \mathrm{l} 0.1 \%$ crystal violet solution (Merck) for $30 \mathrm{~min}$. The plate was washed with water and air-dried. Stained biofilms were dissolved in $200 \mu \mathrm{l}$ DMSO and the $A_{595}$ was measured using a microplate reader (BioTek). The relative percentage of biofilm formation was defined as: (mean $A_{595}$ of treated well/mean $A_{595}$ of control well) $\times 100$.

Effect of $R$. tomentosa ethanol extract, rhodomyrtone and vancomycin on established biofilms. Established biofilms were grown as described by Kuźma et al. (2007). Two hundred microlitres of growing culture $\left(10^{6}\right.$ c.f.u. $\left.\mathrm{ml}^{-1}\right)$ was transferred to a 96 -well microtitre plate and incubated at $37{ }^{\circ} \mathrm{C}$ for $24 \mathrm{~h}$ and 5 days. For 5 day biofilms, planktonic cells were removed and fresh TSB was added daily. After incubation, the medium was removed and the wells were rinsed twice with PBS. TSB $(180 \mu \mathrm{l})$ and $20 \mu \mathrm{l}$ of the test agents at different concentrations were added. After incubation at $37{ }^{\circ} \mathrm{C}$ for $24 \mathrm{~h}$, the medium was removed and replaced with $200 \mu \mathrm{l}$ PBS

Table 2. Effect of $R$. tomentosa ethanol extract, rhodomyrtone and vancomycin on biofilm formation of Staphylococcus aureus

Values with different superscripts differ significantly (Duncan's test; $P<0.05)$. Biofilm formation was measured relative to a positive control with no treatment $(100 \%)$.

\begin{tabular}{|c|c|c|c|c|}
\hline \multirow[t]{2}{*}{ Isolate } & \multirow[t]{2}{*}{ Agent $^{*}$} & \multicolumn{3}{|c|}{ Biofilm formation (\%) } \\
\hline & & $0.5 \times \mathrm{MIC}$ & $0.25 \times \mathrm{MIC}$ & $0.125 \times \mathrm{MIC}$ \\
\hline \multirow[t]{3}{*}{ NPRC 310} & E & $96.8 \pm 5.6^{a}$ & $98.2 \pm 5.1^{a}$ & $100.8 \pm 3.7^{a}$ \\
\hline & $\mathrm{R}$ & $90.9 \pm 4.2^{a}$ & $91.8 \pm 4.2^{a}$ & $105.7 \pm 4.2^{a}$ \\
\hline & $\mathrm{V}$ & $107.4 \pm 13.3^{a}$ & $109.1 \pm 6.3^{a}$ & $109.0 \pm 13.9^{a}$ \\
\hline \multirow[t]{3}{*}{ NPRC 313} & E & $119.8 \pm 6.8^{f}$ & $119.9 \pm 6.3^{f}$ & $115.4 \pm 6.9^{e f}$ \\
\hline & $\mathrm{R}$ & $56.9 \pm 8.6^{a}$ & $99.2 \pm 6.3^{d e}$ & $93.2 \pm 3.1^{c d}$ \\
\hline & $\mathrm{V}$ & $69.0 \pm 9.1^{a b}$ & $75.1 \pm 9.8^{a b c}$ & $85.9 \pm 10.3^{b d}$ \\
\hline \multirow[t]{3}{*}{ NPRC 326} & $\mathrm{E}$ & $67.6 \pm 8.0^{a b}$ & $63.4 \pm 3.6^{a}$ & $68.9 \pm 3.4^{a b c}$ \\
\hline & $\mathrm{R}$ & $83.6 \pm 4.7^{c d}$ & $89.0 \pm 4.4^{d}$ & $86.6 \pm 3.1^{d}$ \\
\hline & V & $80.3 \pm 1.7^{b c d}$ & $91.9 \pm 6.8^{d}$ & $95.8 \pm 7.2^{d}$ \\
\hline \multirow[t]{3}{*}{ NPRC 334} & $\mathrm{E}$ & $77.5 \pm 7.9^{a}$ & $75.6 \pm 7.6^{a}$ & $91.9 \pm 11.3^{a b}$ \\
\hline & $\mathrm{R}$ & $76.3 \pm 10.7^{a}$ & $119.5 \pm 0.8^{d}$ & $114.2 \pm 7.1^{c d}$ \\
\hline & $\mathrm{V}$ & $95.0 \pm 10.0^{a b c}$ & $110.1 \pm 9.5^{b c d}$ & $119.5 \pm 7.7^{d}$ \\
\hline \multirow[t]{3}{*}{ NPRC 361} & $\mathrm{E}$ & $90.6 \pm 3.8^{b}$ & $91.7 \pm 1.4^{b}$ & $93.7 \pm 4.4^{b}$ \\
\hline & $\mathrm{R}$ & $59.9 \pm 0.6^{a}$ & $97.5 \pm 4.0^{b}$ & $112.3 \pm 8.0^{c d}$ \\
\hline & $\mathrm{V}$ & $91.0 \pm 1.0^{b}$ & $104.1 \pm 8.8^{b c}$ & $124.4 \pm 6.4^{d}$ \\
\hline \multirow{3}{*}{$\begin{array}{r}\text { ATCC } \\
25923\end{array}$} & $\mathrm{E}$ & $82.7 \pm 4.1^{a b}$ & $93.0 \pm 1.7^{b c}$ & $104.5 \pm 1.2^{b c}$ \\
\hline & $\mathrm{R}$ & $80.5 \pm 1.4^{a b}$ & $108.8 \pm 1.0^{c}$ & $101.7 \pm 2.5^{b c}$ \\
\hline & $\mathrm{V}$ & $62.5 \pm 7.5^{a}$ & $82.9 \pm 8.3^{a b}$ & $80.6 \pm 9.0^{a b}$ \\
\hline
\end{tabular}

${ }^{\star}$ E, Ethanol extract; R, rhodomyrtone; V, vancomycin. supplemented with $10 \mu \mathrm{l}$ 3-(4,5-dimethylthiazol-2-yl)-2,5-diphenyltetrazolium bromide (MTT, $5 \mathrm{mg} \mathrm{ml} \mathrm{m}^{-1}$; Sigma) and further incubated at $37{ }^{\circ} \mathrm{C}$ for $2 \mathrm{~h}$. The insoluble purple formazan was obtained by cleavage of MTT by the dehydrogenase enzyme of living staphylococcal cells. The formazan crystals were dissolved in DMSO and the $A_{595}$ was determined. The viability percentage of biofilm was defined as: (mean $A_{595}$ of treated well/mean $A_{595}$ of control well) $\times 100$

Scanning electron microscopy. Staphylococcus epidermidis ATCC 35984 was used to study the appearance of established biofilm on polystyrene discs. After incubation for $24 \mathrm{~h}$ and 5 days, the discs were washed three times with PBS. Rhodomyrtone in TSB was added and the discs were incubated at $37{ }^{\circ} \mathrm{C}$ for $24 \mathrm{~h}$. The discs were washed three times with PBS, fixed in $2 \%$ glutaraldehyde (Electron Microscopy Sciences) in PBS for $2 \mathrm{~h}$, washed with PBS and then post-fixed in $4 \%$ osmium tetroxide (Electron Microscopy Sciences) in PBS for $1 \mathrm{~h}$. After washing with distilled water, the specimens were dehydrated in a graded ethanol series (50-100\%), mounted on aluminium stubs, allowed to dry and then coated with gold. The samples were examined under a scanning electron microscope (Quanta 400 FEG; FEI)

Table 3. Effect of $R$. tomentosa ethanol extract, rhodomyrtone and vancomycin on biofilm formation of Staphylococcus epidermidis

Values with different superscripts differ significantly (Duncan's test; $P<0.05)$. Biofilm formation was measured relative to a positive control with no treatment $(100 \%)$.

\begin{tabular}{|c|c|c|c|c|}
\hline \multirow[t]{2}{*}{ Isolate } & \multirow[t]{2}{*}{ Agent $^{*}$} & \multicolumn{3}{|c|}{ Biofilm formation (\%) } \\
\hline & & $0.5 \times \mathrm{MIC}$ & $0.25 \times \mathrm{MIC}$ & $0.125 \times \mathrm{MIC}$ \\
\hline \multirow{3}{*}{$\begin{array}{c}\text { NPRC } \\
511\end{array}$} & E & $85.6 \pm 4.6^{a}$ & $90.4 \pm 7.2^{a}$ & $94.8 \pm 8.6^{a}$ \\
\hline & $\mathrm{R}$ & $85.8 \pm 11.2^{a}$ & $85.0 \pm 1.9^{a}$ & $92.3 \pm 6.2^{a}$ \\
\hline & V & $91.8 \pm 3.2^{a}$ & $83.9 \pm 1.6^{a}$ & $93.2 \pm 2.3^{a}$ \\
\hline \multirow{3}{*}{$\begin{array}{c}\text { NPRC } \\
522\end{array}$} & $\mathrm{E}$ & $44.9 \pm 2.5^{a}$ & $53.4 \pm 5.3^{a}$ & $76.3 \pm 2.6^{b}$ \\
\hline & $\mathrm{R}$ & $48.3 \pm 7.1^{a}$ & $87.9 \pm 8.7^{b c}$ & $92.1 \pm 6.9^{c}$ \\
\hline & $\mathrm{V}$ & $95.1 \pm 3.2^{c}$ & $99.7 \pm 0.5^{c}$ & $98.3 \pm 2.5^{c}$ \\
\hline \multirow{3}{*}{$\begin{array}{c}\text { NPRC } \\
535\end{array}$} & $\mathrm{E}$ & $46.0 \pm 0.5^{a}$ & $56.4 \pm 1.3^{b}$ & $57.5 \pm 0.8^{b c}$ \\
\hline & $\mathrm{R}$ & $67.2 \pm 4.6^{c}$ & $95.4 \pm 3.1^{e}$ & $88.6 \pm 0.9^{d e}$ \\
\hline & $\mathrm{V}$ & $86.4 \pm 4.2^{d e}$ & $87.6 \pm 5.3^{d e}$ & $82.2 \pm 4.5^{d}$ \\
\hline \multirow{3}{*}{$\begin{array}{c}\text { NPRC } \\
576\end{array}$} & $\mathrm{E}$ & $31.8 \pm 5.7^{a}$ & $42.3 \pm 3.9^{a b}$ & $52.2 \pm 1.8^{b}$ \\
\hline & $\mathrm{R}$ & $68.2 \pm 4.9^{c}$ & $67.3 \pm 6.1^{c}$ & $67.6 \pm 2.6^{c}$ \\
\hline & V & $101.8 \pm 5.2^{d}$ & $109.5 \pm 3.3^{d}$ & $104.8 \pm 4.4^{d}$ \\
\hline \multirow{3}{*}{$\begin{array}{c}\text { NPRC } \\
585\end{array}$} & $\mathrm{E}$ & $24.3 \pm 5.4^{a}$ & $34.8 \pm 3.1^{b}$ & $62.2 \pm 3.2^{c}$ \\
\hline & $\mathrm{R}$ & $82.3 \pm 1.3^{d}$ & $105.7 \pm 1.6^{e}$ & $109.0 \pm 2.8^{e}$ \\
\hline & $\mathrm{V}$ & $102.4 \pm 4.9^{e}$ & $108.5 \pm 0.4^{e}$ & $101.8 \pm 3.9^{e}$ \\
\hline \multirow{3}{*}{$\begin{array}{r}\text { ATCC } \\
35984\end{array}$} & E & $43.7 \pm 8.1^{a}$ & $103.1 \pm 6.4^{b c}$ & $102.3 \pm 5.9^{b c}$ \\
\hline & $\mathrm{R}$ & $85.5 \pm 0.7^{b}$ & $96.0 \pm 5.6^{b c}$ & $103.3 \pm 6.2^{b c}$ \\
\hline & $\mathrm{V}$ & $102.4 \pm 3.2^{b c}$ & $104.2 \pm 3.3^{c}$ & $104.4 \pm 1.6^{c}$ \\
\hline
\end{tabular}

${ }^{\star} \mathrm{E}$, Ethanol extract; R, rhodomyrtone; $\mathrm{V}$, vancomycin. 
Statistical analysis. Statistical analysis was performed using analysis of variance. Comparisons between means were carried out according to Duncan's test. Differences were considered significant at $P<0.05$.

\section{RESULTS}

\section{MICs and MBCs}

The MIC and MBC values of the R. tomentosa ethanol extract against the clinical isolates ranged from 32 to $512 \mu \mathrm{g} \mathrm{ml}^{-1}$. Interestingly, the MIC and MBC values of rhodomyrtone ranged from 0.25 to $2.0 \mu \mathrm{g} \mathrm{ml} \mathrm{m}^{-1}$, which were similar to those of vancomycin $\left(0.5-4.0 \mu \mathrm{g} \mathrm{ml}^{-1}\right)$ (Table 1).

\section{Time-kill study}

The number of viable cells of Staphylococcus aureus ATCC 25923 after exposure to rhodomyrtone at a concentration of $4 \times$ MIC decreased by at least $3 \operatorname{logs}$ within $3 \mathrm{~h}$ (Fig. 1a), whilst it took almost $13 \mathrm{~h}$ to reduce the numbers of
Staphylococcus epidermidis ATCC 35984 to the same level (Fig. 1b).

\section{Effect of $R$. tomentosa ethanol extract, rhodomyrtone and vancomycin on biofilm formation}

Treatment with the $R$. tomentosa ethanol extract and rhodomyrtone at $0.5 \times$ and $0.25 \times \mathrm{MIC}$ was found to be effective in reducing biofilm formation in most of the Staphylococcus aureus isolates. At $0.5 \times \mathrm{MIC}$, rhodomyrtone could reduce biofilm production in all isolates, whilst the ethanol extract and vancomycin reduced biofilm formation in most but not all of the isolates at this concentration (Table 2). For Staphylococcus epidermidis, the ethanol extract at $0.5 \times$ and $0.25 \times$ MIC clearly demonstrated a better ability to reduce biofilm formation than rhodomyrtone and vancomycin. At $0.5 \times$ MIC, ethanol extract and rhodomyrtone reduced biofilm formation in all six isolates, whilst at $0.25 \times$ MIC, they each inhibited biofilm formation in five of the six isolates. Vancomycin reduced biofilm formation in three of the six isolates at $0.5 \times$ and $0.25 \times$ MIC (Table 3 ). (a)

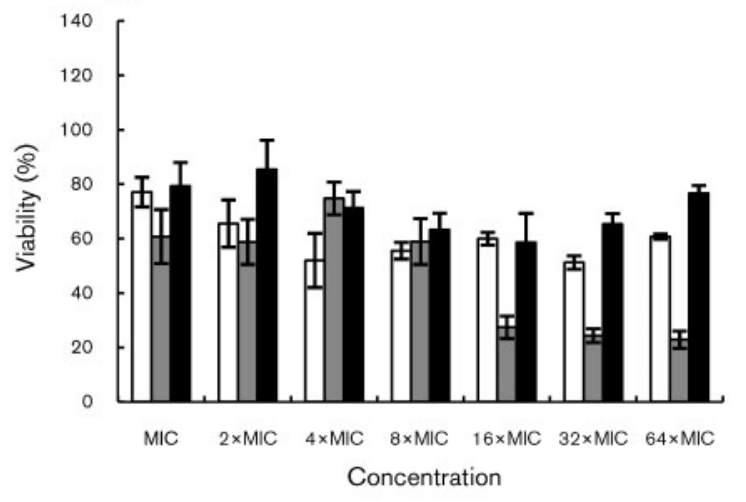

(c)

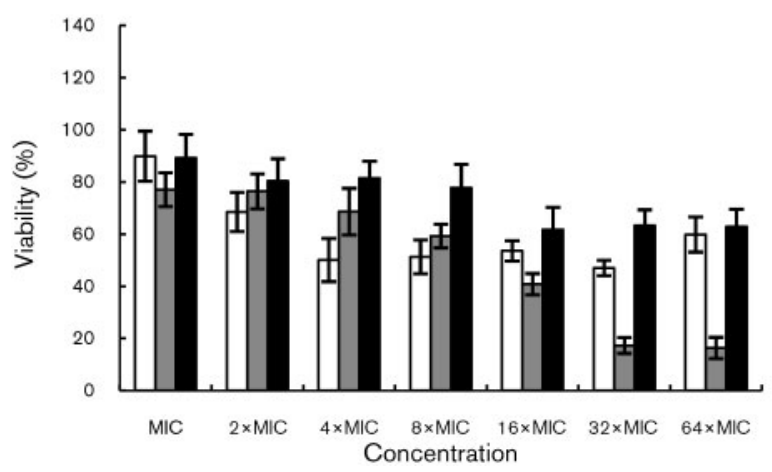

(b)

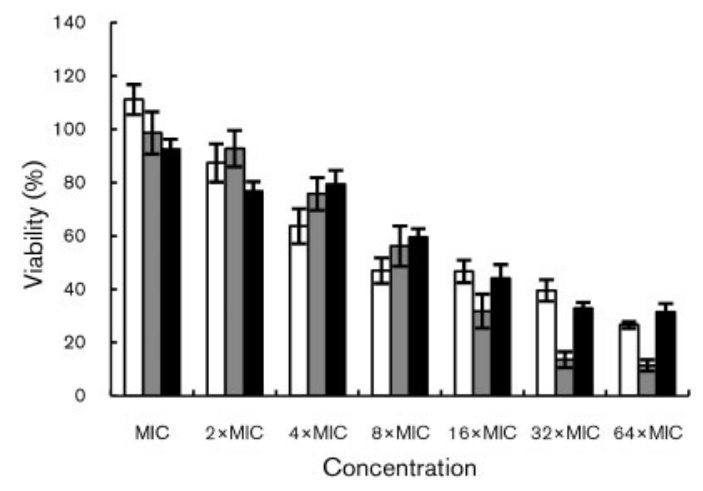

(d)

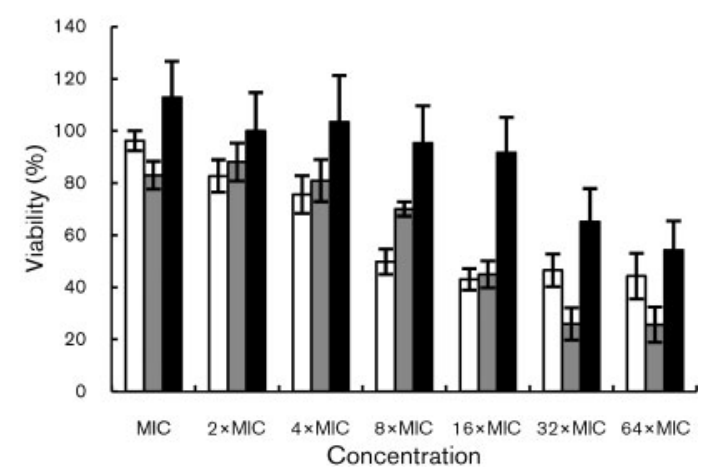

Fig. 2. Effect of $R$. tomentosa ethanol extract (open bars), rhodomyrtone (shaded bars) and vancomycin (black bars) on Staphylococcus aureus viability for 24 h biofilm of NPRC 361 (a), 24 h biofilm of ATCC 25923 (b), 5-day biofilm of NPRC 361 (c) and 5-day biofilm of ATCC 25923 (d). 
The impact of the compounds on biofilm formation was found to be dose-dependent.

\section{Effect of $R$. tomentosa ethanol extract, rhodomyrtone and vancomycin on established biofilms}

Ethanol extract, rhodomyrtone and vancomycin exhibited antibiofilm activity on established biofilms in a dosedependent manner. The results demonstrated that rhodomyrtone and the ethanol extract were more efficient than vancomycin in killing organisms in an established biofilm. Rhodomyrtone at 16-64 $\times$ MIC demonstrated better efficiency than the ethanol extract and vancomycin at reducing the bacterial viability of $24 \mathrm{~h}$ and 5-day biofilms of Staphylococcus aureus $(P<0.05)$ (Fig. 2). For Staphylococcus epidermidis, significant differences in cell viability were observed among different test antibacterial agents at $64 \times$ MIC $(P<0.05)$. At $8 \times$ MIC, rhodomyrtone exhibited a better activity than the ethanol extract and vancomycin in reducing cell viability of $24 \mathrm{~h}$ biofilms $(P<0.05)$ (Fig. 3$)$. The survival of 5-day biofilms was $58.5 \%$ in the presence of rhodomyrtone at $64 \times$ MIC. Vancomycin demonstrated no effect on 5-day biofilm established organisms. It should be noted that the compounds demonstrated better activity in killing the organisms in $24 \mathrm{~h}$ biofilms than those in 5-day biofilms.

\section{Scanning electron microscopy}

The structure of $24 \mathrm{~h}$ established biofilms is shown in Fig. 4. Treatment of the organisms with rhodomyrtone at $16 \times$ MIC damaged the biofilm structure (Fig. 4b) and the bacterial population. Well-organized biofilm layers were still observed, although some bacterial cells were destroyed after treatment with vancomycin at $16 \times$ MIC (Fig. 4c). For 5-day biofilms, proliferating bacteria covered the whole surface with a large amount of biofilm and polysaccharide matrix after treatment with $1 \%$ DMSO (Fig. 4d) and vancomycin at $64 \times$ MIC (Fig. $4 \mathrm{f}$ ). In contrast, treatment with rhodomyrtone at $64 \times$ MIC demonstrated destruction of the established staphylococcal biofilm (Fig. 4e).

\section{DISCUSSION}

The $R$. tomentosa ethanol extract and rhodomyrtone both possessed strong activity against Staphylococcus aureus and (a)

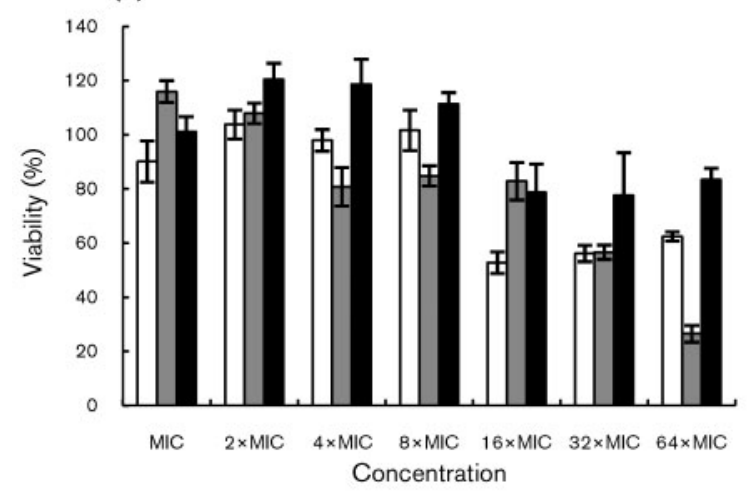

(c)

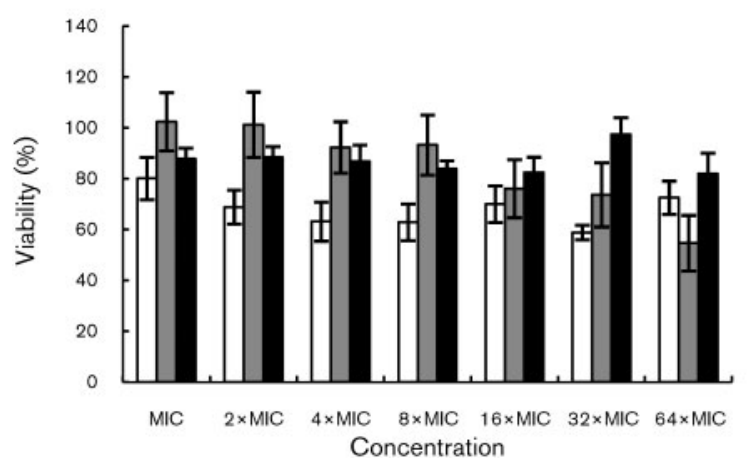

(b)

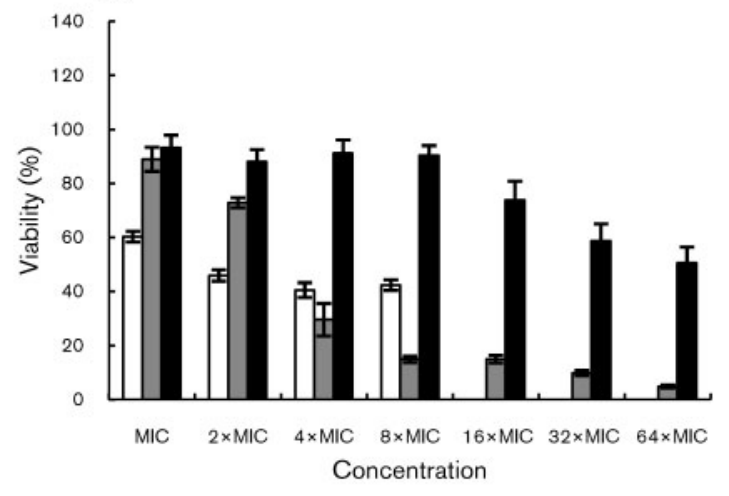

(d)

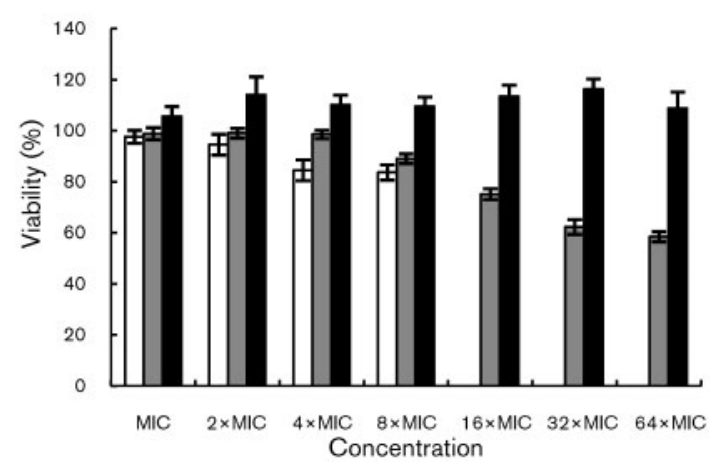

Fig. 3. Effect of $R$. tomentosa ethanol extract (open bars), rhodomyrtone (shaded bars) and vancomycin (black bars) on Staphylococcus epidermidis viability for $24 \mathrm{~h}$ biofilm of NPRC 522 (a), $24 \mathrm{~h}$ biofilm of ATCC 35984 (b), 5-day biofilm of NPRC 522 (c) and 5-day biofilm of ATCC 35984 (d). 

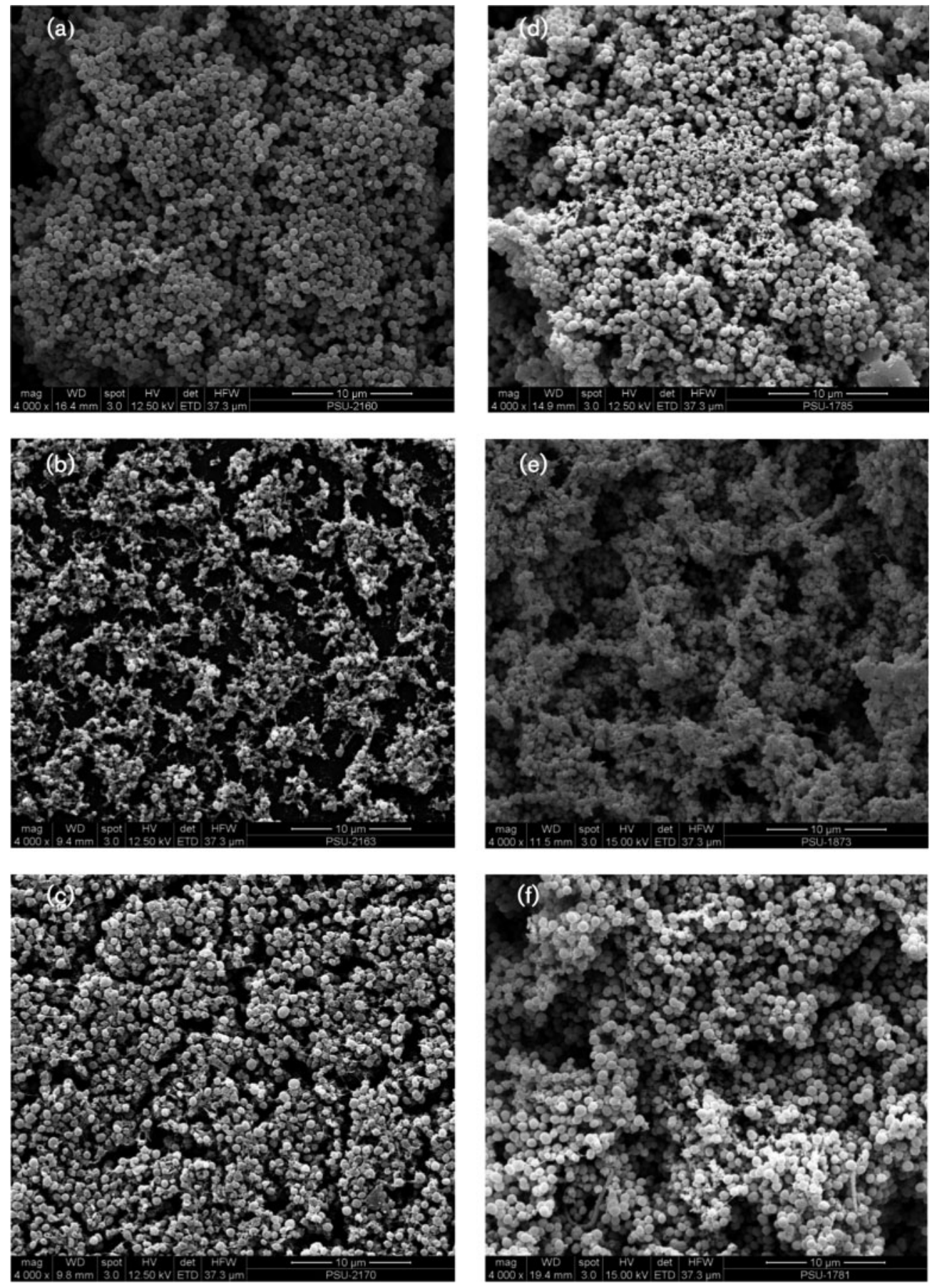

Fig. 4. Scanning electron micrographs of Staphylococcus epidermidis ATCC 35984 biofilm after exposure to the test antibacterial agents. (a) Control; (b) $24 \mathrm{~h}$ biofilm exposed to $16 \times \mathrm{MIC}$ rhodomyrtone; (c) $24 \mathrm{~h}$ biofilm exposed to $16 \times \mathrm{MIC}$ vancomycin; (d) 5-day biofilm control (exposed to DMSO); (e) 5-day biofilm exposed to 64× MIC rhodomyrtone; (f) 5-day biofilm exposed to $64 \times$ MIC vancomycin.

Staphylococcus epidermidis. In addition to direct antibacterial activity, antibacterial agents that are able to prevent or interfere with biofilm formation and are active against biofilm-forming organisms would be of considerable advantage in treatment of infections. The $R$. tomentosa ethanol extract was able to reduce biofilm formation more readily than rhodomyrtone and vancomycin. Limsuwan \& Voravuthikunchai (2008) previously demonstrated the 
antibiofilm property of $R$. tomentosa ethanol extract against Streptococcus pyogenes. Active components in this plant such as tannins (Liu et al., 1998) and triterpenoids (Hui et al., 1975) possibly affect biofilm formation. The mechanisms of the antimicrobial action of tannins may be related to the ability to inactivate microbial adhesins, enzymes and cell envelope transport proteins (Cowan, 1999). Protein levels during initial biofilm development were found to decrease fivefold after treatment with carvacrol, a compound in the terpenoid group (Knowles et al., 2005).

Studies of plant natural products on biofilm eradication have been reported. Their actions on biofilm may involve the inhibition of cell accumulation, interrupting the biofilm structure, destruction of extracellular matrix, dissemination through the biofilm extracellular matrix and subsequent damage due to their powerful antimicrobial activity (Nostro et al., 2007; Kwieciński et al., 2009; Marino et al., 2010).

The ethanol extract and rhodomyrtone demonstrated a better ability than vancomycin to reduce the viability of biofilm-grown cells. Although planktonic bacterial cells were rapidly exposed to vancomycin, bacterial cells inside biofilm were only exposed slowly to vancomycin because of its reduced rate of penetration, resulting in gradual exposure of the bacterial cells to low concentrations (Jefferson et al., 2005). A low molecular mass $\left(442.6 \mathrm{~g} \mathrm{~mol}^{-1}\right.$ ) has been reported for rhodomyrtone (Salni et al., 2002). Thus, it can be speculated that this compound could easily penetrate the biofilm matrix with a high accumulation rate, resulting in efficient elimination of the bacterial cells.

Although rhodomyrtone exhibited potential activity with a very low MIC value, the mechanisms of action of this compound are still unclear. Proteomic studies on cellular proteins in meticillin-resistant Staphylococcus aureus treated with rhodomyrtone have suggested changes in proteins related to cell-wall biosynthesis and cell division, protein degradation, stress response and oxidative stress, cell-surface antigen and virulence factors, and various metabolic pathways (Sianglum et al., 2011). In addition, glyceraldehyde-3phosphate dehydrogenase, CAMP factor and streptococcal pyrogenic exotoxin $\mathrm{C}$ were reduced in rhodomyrtonetreated Streptococcus pyogenes cells (Limsuwan et al., 2011).

In conclusion, $R$. tomentosa ethanol extract and rhodomyrtone possessed strong antibacterial activity. Moreover, rhodomyrtone had significant effects on both biofilm formation and the survival of the organisms in the established biofilms. These results support the application of rhodomyrtone as an alternative agent against biofilmproducing staphylococcal infections.

\section{ACKNOWLEDGEMENTS}

This work was supported by the Strategic Scholarships for Frontier Research Networks for the Joint PhD Program Thai Doctoral degree, Office of the Higher Education Commission, Thailand, and the National Research University Project of Thailand's Office of the Higher Education Commission.

\section{REFERENCES}

Cerca, N., Martins, S., Cerca, F., Jefferson, K. K., Pier, G. B., Oliveira, R. \& Azeredo, J. (2005). Comparative assessment of antibiotic susceptibility of coagulase-negative staphylococci in biofilm versus planktonic culture as assessed by bacterial enumeration or rapid XTT colorimetry. J Antimicrob Chemother 56, 331-336.

CLSI (2006). Methods for Dilution Antimicrobial Susceptibility Tests for Bacteria that Grow Aerobically, 7th edn; Approved Standard. M7-A7. Wayne, PA: Clinical and Laboratory Standards Institute.

Cowan, M. M. (1999). Plant products as antimicrobial agents. Clin Microbiol Rev 12, 564-582.

Frank, K. L., Reichert, E. J., Piper, K. E. \& Patel, R. (2007). In vitro effects of antimicrobial agents on planktonic and biofilm forms of Staphylococcus lugdunensis clinical isolates. Antimicrob Agents Chemother 51, 888-895.

Götz, F. (2002). Staphylococcus and biofilms. Mol Microbiol 43, 13671378.

Hui, W.-H., Li, M.-M. \& Luk, K. (1975). Triterpenoids and steroids from Rhodomyrtus tomentosa. Phytochemistry 14, 833-834.

Jefferson, K. K., Goldmann, D. A. \& Pier, G. B. (2005). Use of confocal microscopy to analyze the rate of vancomycin penetration through Staphylococcus aureus biofilms. Antimicrob Agents Chemother 49, 2467-2473.

Karaolis, D. K., Rashid, M. H., Chythanya, R., Luo, W., Hyodo, M. \& Hayakawa, Y. (2005). c-di-GMP (3'-5'-cyclic diguanylic acid) inhibits Staphylococcus aureus cell-cell interactions and biofilm formation. Antimicrob Agents Chemother 49, 1029-1038.

Knowles, J. R., Roller, S., Murray, D. B. \& Naidu, A. S. (2005). Antimicrobial action of carvacrol at different stages of dual-species biofilm development by Staphylococcus aureus and Salmonella enterica serovar Typhimurium. Appl Environ Microbiol 71, 797-803.

Kuźma, L., Rózalski, M., Walencka, E., Rózalska, B. \& Wysokińska, H. (2007). Antimicrobial activity of diterpenoids from hairy roots of Salvia sclarea L.: salvipisone as a potential anti-biofilm agent active against antibiotic resistant staphylococci. Phytomedicine 14, 31-35.

Kwieciński, J., Eick, S. \& Wójcik, K. (2009). Effects of tea tree (Melaleuca alternifolia) oil on Staphylococcus aureus in biofilms and stationary growth phase. Int J Antimicrob Agents 33, 343-347.

Limsuwan, S. \& Voravuthikunchai, S. P. (2008). Boesenbergia pandurata (Roxb.) Schltr., Eleutherine americana Merr. and Rhodomyrtus tomentosa (Aiton) Hassk. as antibiofilm producing and antiquorum sensing in Streptococcus pyogenes. FEMS Immunol Med Microbiol 53, 429-436.

Limsuwan, S., Trip, E. N., Kouwen, T. R., Piersma, S., Hiranrat, A., Mahabusarakam, W., Voravuthikunchai, S. P., van Dijl, J. M. \& Kayser, O. (2009). Rhodomyrtone: a new candidate as natural antibacterial drug from Rhodomyrtus tomentosa. Phytomedicine 16, 645-651.

Limsuwan, S., Hesseling-Meinders, A., Voravuthikunchai, S. P., van Dijl, J. M. \& Kayser, O. (2011). Potential antibiotic and antiinfective effects of rhodomyrtone from Rhodomyrtus tomentosa (Aiton) Hassk. on Streptococcus pyogenes as revealed by proteomics. Phytomedicine 18, 934-940.

Liu, Y., Hou, A., Ji, C. \& Wu, Y. (1998). Isolation and structure of hydrolysable tannins from Rhodomyrtus tomentosa. Tianran Chanwu Yanjiu Yu Kaifa 10, 14-19.

Mah, T.-F. C. \& O'Toole, G. A. (2001). Mechanisms of biofilm resistance to antimicrobial agents. Trends Microbiol 9, 34-39.

Marino, A., Bellinghieri, V., Nostro, A., Miceli, N., Taviano, M. F., Güvenç, A. \& Bisignano, G. (2010). In vitro effect of branch extracts 
of Juniperus species from Turkey on Staphylococcus aureus biofilm. FEMS Immunol Med Microbiol 59, 470-476.

Nishimura, S., Tsurumoto, T., Yonekura, A., Adachi, K. \& Shindo, H. (2006). Antimicrobial susceptibility of Staphylococcus aureus and Staphylococcus epidermidis biofilms isolated from infected total hip arthroplasty cases. J Orthop Sci 11, 46-50.

Nostro, A., Sudano Roccaro, A., Bisignano, G., Marino, A., Cannatelli, M. A., Pizzimenti, F. C., Cioni, P. L., Procopio, F. \& Blanco, A. R. (2007). Effects of oregano, carvacrol and thymol on Staphylococcus aureus and Staphylococcus epidermidis biofilms. J Med Microbiol 56, 519-523.

Saising, J., Hiranrat, A., Mahabusarakam, W., Ongsakul, M. \& Voravuthikunchai, S. P. (2008). Rhodomyrtone from Rhodomyrtus tomentosa (Aiton) Hassk. as a natural antibiotic for staphylococcal cutaneous infections. J Health Sci 54, 589-595.
Salni, D., Sargent, M. V., Skelton, B. W., Soediro, I., Sutisna, M., White, A. H. \& Yulinah, E. (2002). Rhodomyrtone, an antibiotic from Rhodomyrtus tomentosa. Aust J Chem 55, 229-232.

Sianglum, W., Srimanote, P., Wonglumsom, W., Kittiniyom, K. \& Voravuthikunchai, S. P. (2011). Proteome analyses of cellular proteins in methicillin-resistant Staphylococcus aureus treated with rhodomyrtone, a novel antibiotic candidate. PLOS ONE 6, e16628.

Voravuthikunchai, S. P., Dolah, S. \& Charernjiratrakul, W. (2010). Control of Bacillus cereus in foods by Rhodomyrtus tomentosa (Ait.) Hassk. leaf extract and its purified compound. J Food Prot 73, 19071912.

Wang, X., Yao, X., Zhu, Z., Tang, T., Dai, K., Sadovskaya, I., Flahaut, S. \& Jabbouri, S. (2009). Effect of berberine on Staphylococcus epidermidis biofilm formation. Int J Antimicrob Agents 34, 60-66. 